\title{
Sevoflurane and isoflurane decrease TNF- $\alpha$-induced gene expression in human monocytic THP-1 cells: Potential role of intracellular IKB $\alpha$ regulation
}

\author{
KIM A. BOOST ${ }^{1}$, TOBIAS LEIPOLD ${ }^{2}$, PATRICK SCHEIERMANN ${ }^{1}$, SANDRA HOEGL $^{1}$, \\ CHRISTIAN D. SADIK ${ }^{3}$, CHRISTIAN HOFSTETTER ${ }^{2}$ and BERNHARD ZWISSLER ${ }^{1}$ \\ ${ }^{1}$ Department of Anesthesiology, Ludwig-Maximilians-University, Munich; ${ }^{2}$ Department of \\ Anesthesiology, Intensive Care and Pain Therapy, ${ }^{3}$ Pharmazentrum Frankfurt/ZAFES, \\ Johann Wolfgang Goethe University, Frankfurt am Main, Germany
}

Received December 3, 2008; Accepted January 26, 2009

DOI: 10.3892/ijmm_00000178

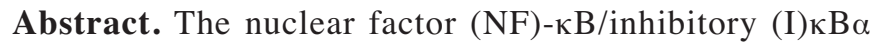
pathway is one of the most important intracellular signal transduction pathways during inflammation which is induced by a variety of major early response cytokines. Recent studies suggest that volatile anesthetics interfere with inflammatory cytokine production through inhibition of intracellular signal transduction pathways. We, therefore, aimed to investigate the effects of the volatile anesthetics sevoflurane and isoflurane on NF- $\mathrm{KB} / \mathrm{I} \mathrm{\kappa B} \alpha$-dependent intracellular signal transduction in human monocytic THP-1 cells induced by tumor necrosis factor- $\alpha$ (TNF- $\alpha$ ) and production of interleukin-8 (IL-8) and downstream heme oxygenase-1 (HO-1). THP-1 cells, a human monocytic cell line, were used in an in vitro model which enables the exposure to volatile anesthetics. Using this model, THP-1 cells were subjected to sevoflurane or isoflurane exposure (1 MAC each) and were stimulated with TNF- $\alpha$ (50 or $100 \mathrm{ng} / \mathrm{ml}$ ). Compared to untreated cells, expression of intracellular HO-1-protein and release of IL-8 into cell culture supernatants and corresponding mRNA expression were attenuated in THP-1 cells exposed to sevoflurane and isoflurane, respectively. Moreover, translocation of NF-кB and degradation of І $\mathrm{B} \alpha$ were markedly reduced by both anesthetics. Notably, under unstimulated conditions, exposure to sevoflurane induced a sustained upregulation of the IкB $\alpha$ content in THP- 1 cells. We demonstrated inhibition of TNF- $\alpha$-induced gene expression and release of IL- 8 and HO-1 in human monocytic THP-1 cells exposed to both
\end{abstract}

Correspondence to: Dr Kim Alexander Boost, Klinik für Anästhesiologie der Ludwig-Maximilians-Universität München, Klinikum Grosshadern, Marchioninistr. 15, D-81377 München, Germany

E-mail: kim.boost@med.uni-muenchen.de

Key words: volatile anesthetics, nuclear factor-кB, ТНР-1, interleukin- 8 , heme oxygenase-1 volatile anesthetics. This was associated with an upregulated intracellular ІкB $\alpha$ content followed by decreased NF-кB translocation. This was more sustained during exposure to sevoflurane and may provide an additional intracellular mechanism for the anti-inflammatory effects associated with sevoflurane administration.

\section{Introduction}

Preconditioning with volatile anesthetics in ischemic situations is well known in the literature and clinical practice $(1,2)$. In this context, extensive analyses have indicated that secretion of inflammatory mediators can be reduced through exposure to volatile anesthetics prior to ischemia and reperfusion $(3,4)$. In addition, it was previously shown that, also in inflammatoryinduced situations of endotoxemia and acute lung injury, exposure to volatile anesthetics similarly attenuated the release of proinflammatory cytokines $(5,6)$.

One of the molecular hallmarks of acute and chronic inflammation is activation of nuclear factor- $\mathrm{\kappa} B(\mathrm{NF}-\kappa \mathrm{B})$, which is a central transcription factor in e.g. tumor necrosis factor- $\alpha$ (TNF- $\alpha)$ and endotoxin-mediated responses $(7,8)$. The most common form of NF- $\mathrm{KB}$ is the $\mathrm{p} 50 / \mathrm{p} 65$ heterodimer which is typically sequestered in the cytoplasm as an inactive complex bound to a member of the inhibitory $\kappa B$ family, most commonly inhibitory $\kappa \mathrm{B} \alpha(\mathrm{I} \kappa \mathrm{B} \alpha)$. The activation of NF- $\kappa \mathrm{B}$ takes route through binding of inflammatory cytokines (e.g. TNF- $\alpha$ ) to extracellular receptors which generate activation of the IкB kinase (IKK) complex (9). Subsequently, the IKK complex phosphorylates IKB $\alpha$ and targets it for ubiquitin-proteasome degradation (10). This immediately triggers nuclear localization of NF- $\mathrm{\kappa B}$ and subsequent activation of gene expression programs leading to the release of acute phase proteins and inflammatory cytokines (11).

In such early stages of acute and chronic inflammation, one of the most important early response cytokines is TNF- $\alpha$ (12). TNF- $\alpha$ stimulates the release and activation of a variety of proinflammatory and apoptotic mediators which enhance and maintain the inflammatory response. This includes 
interleukin-8 (IL-8) and downstream heme oxygenase-1 (HO-1) which are critically involved in mediating and modulating chronic and acute inflammatory responses $(13,14)$.

Volatile anesthetics are known to have anti-inflammatory and preconditioning properties in vitro and in vivo $(15,16)$. There is increasing evidence that these properties are mediated by inhibition of proinflammatory intracellular signal transduction pathways (17). Accordingly, it was demonstrated in animal models of LPS administration that the release of proinflammatory cytokines is markedly reduced by exposure to volatile anesthetics $(5,18)$. Moreover, volatile anesthetics may modulate the immune response by decreasing neutrophil functions (19). Downregulation of cytokine release in response to volatile anesthetics has also been shown for alveolar epithelial cells (20).

The underlying molecular mechanisms initiated by volatile anesthetics are still not fully understood and are under intensive investigation. Therefore, the aim of our study was to examine, in a cell model of inflammation, whether exposure to the volatile anesthetics sevoflurane and isoflurane influences TNF- $\alpha$-induced gene expression and production of downstream mediators in THP- 1 cells. Moreover, the potential of volatile anesthetics to interfere with $\mathrm{NF}-\kappa \mathrm{B} / \mathrm{I} \kappa \mathrm{B} \alpha$ activation was investigated in the current study.

\section{Materials and methods}

Materials. TNF- $\alpha$ was kindly provided by Knoll AG (Ludwigshafen, Germany).

Cultivation of THP-1 cells. Monocytic THP-1 cells were obtained from the German Collection of Microorganisms and Cell Cultures (Braunschweig, Germany). Cells were maintained in culture medium consisting of RPMI-1640 supplemented with $10 \mathrm{mM}$ HEPES, $100 \mathrm{U} \mathrm{ml}^{-1}$ penicillin, $100 \mu \mathrm{g} \mathrm{ml}^{-1}$ streptomycin and $10 \%$ heat-inactivated FCS (Gibco BRL). Cells were maintained in the aforementioned medium using polystyrene flasks (Greiner, Frickenhausen, Germany). For experiments, 5 or $2 \mathrm{ml}$ of cell suspension was seeded into $10-\mathrm{cm}$ or 6 -well polystyrene plates (Greiner) at $10^{6}$ cells $\mathrm{ml}^{-1}$ using supplemented RPMI- 1640 cell culture medium. All incubations were performed at $37^{\circ} \mathrm{C}$ in $5 \% \mathrm{CO}_{2}$.

Exposure to volatile anesthetics and experimental protocol. After cell seeding, THP-1 cells were exposed to either air or a volatile anesthetic/air mixture using a standard or a specifically modified incubator. The specifically modified incubator directs a gas/air mixture into the incubator chamber. The volatile anesthetic concentration was monitored continuously in a closed loop by using a monitor for volatile anesthetics (Vamos, Draeger Medical, Lübeck, Germany). Cells were pre-incubated for $6 \mathrm{~h}$ with 1 minimal alveolar concentration (1 MAC) each of the volatile anesthetics isoflurane or sevoflurane (Abbott, Wiesbaden, Germany) followed by stimulation with TNF- $\alpha$. Stimulation with TNF- $\alpha$ was performed with a concentration of 50 or $100 \mathrm{ng} / \mathrm{ml}$. After $18 \mathrm{~h}$, THP-1 cells and cell culture supernatants were collected for further analysis. For each exposure condition, control samples were obtained simultaneously from THP-1 cells which were cultured and stimulated in a standard $95 \%$ air/5\% $\mathrm{CO}_{2}$ incubator without anesthetic exposure.

Detection of cytokines by ELISA. Cell-free supernatants were collected, and levels of human IL-8 (Pharmingen, Heidelberg, Germany) were determined by ELISA according to the manufacturer's instructions.

Western blot analysis. Briefly, THP-1 cells were lysed on ice in lysis buffer (100 mM NaCl, $20 \mathrm{mM} \mathrm{TriCl,} \mathrm{pH} \mathrm{7.8,} \mathrm{0,1 \%}$ NP-40) supplemented with protease inhibitor cocktail (Roche Molecular Biochemicals) and DTT, $\mathrm{Na}_{3} \mathrm{VO}_{4}, \mathrm{PMSF}$ and $\mathrm{NaF}$ (1 mM each). Homogenates were then centrifuged at 10,000 rpm for $10 \mathrm{~min}$ at $4^{\circ} \mathrm{C}$. Supernatants were collected and stored at $-80^{\circ} \mathrm{C}$ until further analysis. Total protein $(50 \mu \mathrm{g})$ was loaded per lane and separated on 10\% SDS-PAGE gels by standard electrophoresis at $100 \mathrm{~V}$. Proteins were then electrophoretically transferred to a nitrocellulose membrane. The membrane was subsequently blocked in $2 \%$ bovine serum albumin for $1 \mathrm{~h}$ at room temperature and incubated overnight at $4^{\circ} \mathrm{C}$ with primary antibody to: $\mathrm{HO}-1$, rabbit polyclonal antibody (Stressgen, Hamburg, Germany); inhibitor (I)кB $\alpha$, rabbit polyclonal antibody (Santa Cruz Biotechnology, Heidelberg, Germany); and ß-actin, murine monoclonal antibody (Sigma). After washing, horseradish peroxidaseconjugated secondary antibody was added and incubated at room temperature for $1 \mathrm{~h}$. After repeated washing, blots were subsequently developed using an enhanced chemiluminescence detection kit (Amersham) and exposed to autoradiographic film.

Analysis of translocated $N F-\kappa B$ subunit to the nucleus. Nuclear extracts from the monocyte suspension were used for

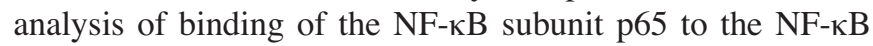
binding sequence 5'-GGGACTTTCC-3'. This was measured using the ELISA-based Trans-AM NF- $\mathrm{B}$ kit (Actif Motif). Then, total protein $(8 \mu \mathrm{g})$ was used for analysis according to the manufacturer's instructions.

Analysis of mRNA expression by quantitative real-time RT$P C R$ analysis. RNA was isolated using Trizol reagent (Gibco BRL) according to the manufacturer's instructions. Total RNA $(1 \mu \mathrm{g})$ was used for quantitative real-time RT-PCR analysis. Primers for IL-8 and HO-1 mRNAs were purchased from Applied Biosystems, Weiterstadt (human IL-8: 5'-ACTGCA-CCT-TCA-CAC-AGA-GCT-GCA-GAA-ATC-3' and human HO-1: 5'-TGC-TCA-ACA-TCC-AGC-TCT-TTGAGG-AGT-TG-3'). mRNA expression was determined by real-time RT-PCR, based on TaqMan methodology, using the ABI PRISM 7700 Sequence Detector (Applied Biosystems) as follows: one initial step at $50^{\circ} \mathrm{C}$ for $2 \mathrm{~min}$ and $95^{\circ} \mathrm{C}$ for $10 \mathrm{~min}$ followed by 40 cycles at $95^{\circ} \mathrm{C}$ for $15 \mathrm{sec}$ and $60^{\circ} \mathrm{C}$ for $1 \mathrm{~min}$. For GAPDH, we used a pre-developed assay according to the manufacturer's instructions (Applied Biosystems).

Statistics. Data were expressed as the mean \pm SD. Statistical analysis was performed with Sigma Stat (SPSS-Jandel 2.0 Scientific, San Jose, CA). Unless otherwise stated, raw data was analyzed by the unpaired Student's t-test. Differences were considered significant at $\mathrm{p} \leq 0.05$. 


\section{A}

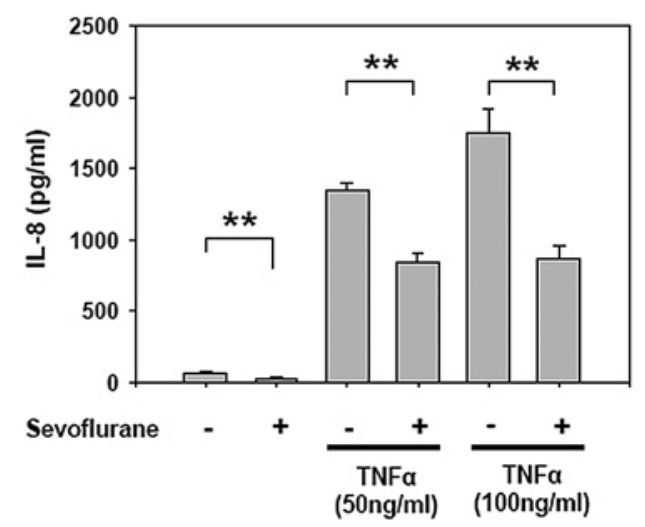

C

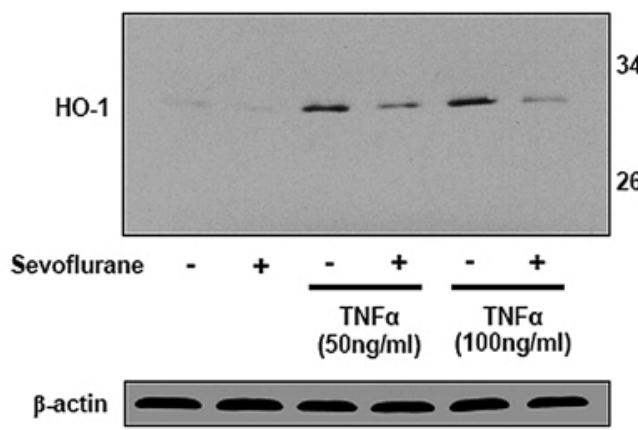

B

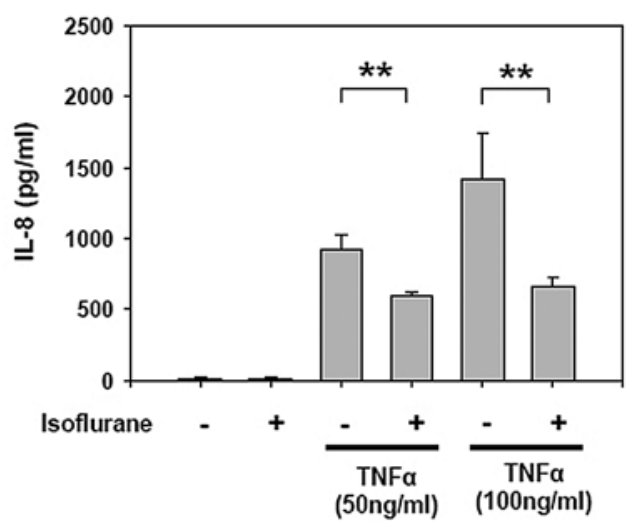

D

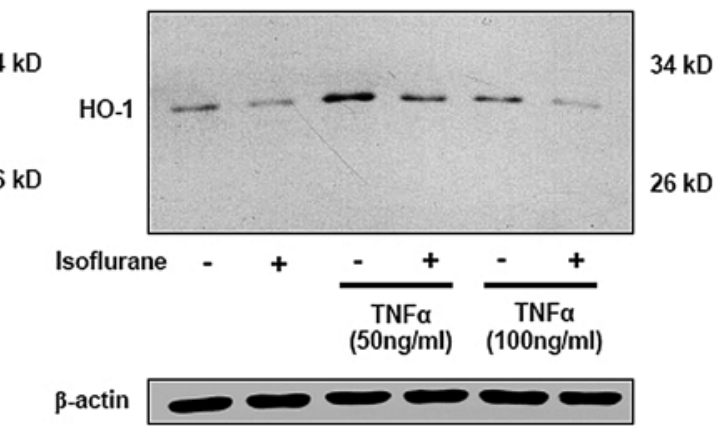

Figure 1. (A and B) Cytokine levels of IL-8 in cell-free culture supernatants determined by ELISA. Cells were exposed to either 1 MAC sevoflurane or isoflurane and stimulated for $16 \mathrm{~h}$ with different concentrations of $\mathrm{TNF}-\alpha$. Data are expressed as mean cytokine concentrations $\pm \mathrm{SD} ;{ }^{*} \mathrm{p}<0.05,{ }^{* *} \mathrm{p}<0.01, \mathrm{n}=6$. (C and D) Intracellular levels of HO-1 expression in THP-1 cells as determined by Western blotting. Cells were exposed to either 1 MAC sevoflurane or isoflurane and stimulated for $16 \mathrm{~h}$ with different concentrations of TNF- $\alpha$. Equal amounts of $50 \mu \mathrm{g}$ of protein were immunoblotted onto nitrocellulose membranes. The data shown are representative of four independent experiments.

\section{Results}

Attenuation of IL-8- and $\mathrm{HO}-1$ release through exposure to sevoflurane and isoflurane. Treatment of THP-1 cells with different doses of TNF- $\alpha$ (50 or $100 \mathrm{ng} / \mathrm{ml})$ induced a marked and dose-dependent increase in the release of IL- 8 into the culture medium (Fig. 1A and B) and increased the intracellular expression of HO-1 (Fig. 1C and D) through upregulation of the corresponding mRNA expression (Fig. 2A-D).

Exposure of the cells to both volatile anesthetics prior to stimulation with TNF- $\alpha$ significantly reduced the release of IL-8 into the culture medium in both dosage groups $(\mathrm{p}<0.01)$ (Fig. 1A and B). Likewise, the intracellular HO-1 expression was markedly reduced compared to untreated cells (Fig. 1C and D).

Notably, sevoflurane additionally exhibited the potential to significantly reduce the basal release of IL- 8 into the culture medium supernatant in unstimulated and exposed cells compared to unstimulated and unexposed cells $(\mathrm{p}<0.01)$ (Fig. 1A). However, levels of IL-8 under these conditions were low and close to the minimal detection range of the ELISA method.

Attenuation of the HO-1 and IL-8 mRNA content in cells exposed to volatile anesthetics. In line with the inhibited release of IL-8 and HO-1, corresponding mRNA levels were also significantly reduced in the cells which were exposed to isoflurane or sevoflurane in both dosage groups (Fig. 2A-D).

Exposure to sevoflurane reduces the translocation of $N F-\kappa B$ to the nucleus via stabilization of $I \kappa B \alpha$. Determination of the intracellular IкB $\alpha$ content in THP- 1 cells by Western blot analysis demonstrated a stabilized $\mathrm{I} \kappa \mathrm{B} \alpha$ content in the cells exposed either to sevoflurane or isoflurane (Fig. 3A and B). 


\section{A}

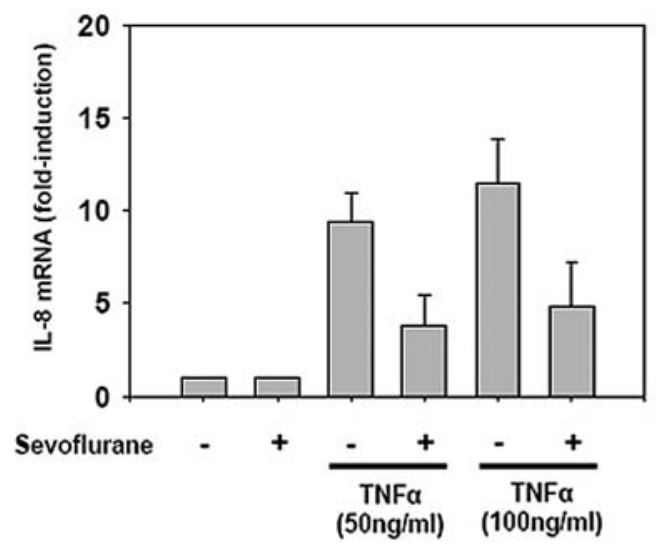

\section{C}

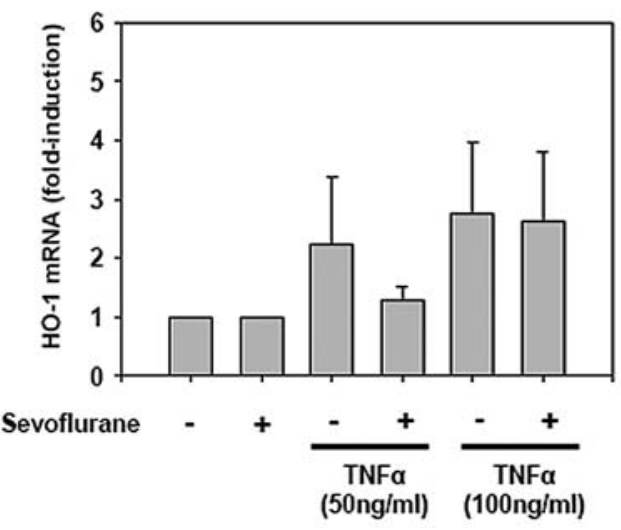

B

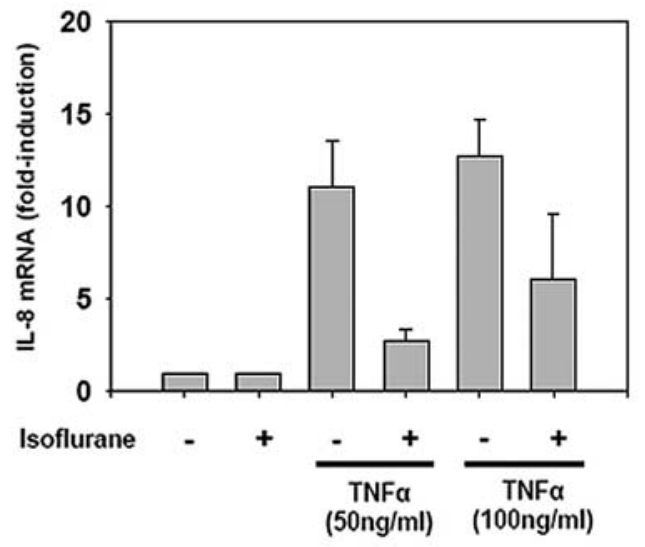

D

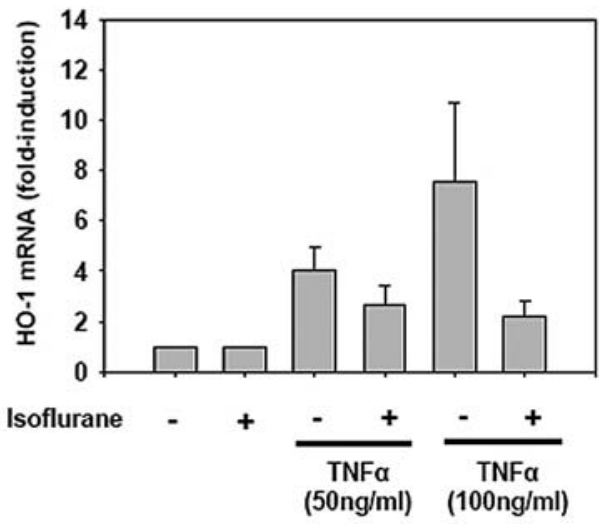

Figure 2. (A and B) mRNA induction in THP-1 cells determined by real-time RT-PCR. RNA was prepared from cell lysates and analyzed for IL-8 mRNA expression by real-time RT-PCR. Cells were exposed to either $1 \mathrm{MAC}$ sevoflurane or isoflurane and stimulated for $16 \mathrm{~h}$ with different concentrations of TNF- $\alpha$. mRNA expression is presented as fold induction and was normalized by GAPDH expression. $\mathrm{n}=3$. (C and D) mRNA induction in THP-1 cells as determined by real-time RT-PCR. Cells were exposed to either 1 MAC sevoflurane or isoflurane and stimulated for $16 \mathrm{~h}$ with different concentrations of TNF- $\alpha$. RNA was prepared from cell lysates and analyzed for HO-1 mRNA expression by real-time RT-PCR. mRNA expression is presented as fold induction and was normalized by GAPDH expression. $n=4$.

Corresponding to these findings, analysis of the intranuclear p65 content demonstrated a significantly reduced translocation of the p65 molecule to the nucleus in cells exposed to sevoflurane or isoflurane compared to untreated cells $(\mathrm{p}<0.01)$ (Fig. 4). In both dosage groups the amount of p65 translocation was reduced close to the basal level.

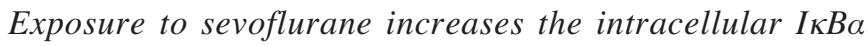
content in untreated cells. Analyses of the intracellular basal levels of IкB $\alpha$ under unstimulated conditions in cells exposed to sevoflurane over $24 \mathrm{~h}$ demonstrated an increased IкB $\alpha$ content with a peak at $8 \mathrm{~h}$ (Fig. 5A). This was not noted when cells were exposed to isoflurane (data not shown).
IL-8 secretion is dependent on $N F-\kappa B$ activation. Coincubation of THP-1 cells with a specific NF- $\mathrm{NB}$ inhibitor (BAY11-7085, Alexis, San Diego, USA) demonstrated reduced IL-8 secretion into the culture medium suggesting a sustained role of this regulatory protein in the context of production of the proinflammatory protein IL-8 (Fig. 5B).

\section{Discussion}

In clinical practice, the anti-inflammatory properties of volatile anesthetics during operative and critical care are increasingly coming to the focus of interest. Studies have indicated that volatile anesthetics can modulate either the 
A

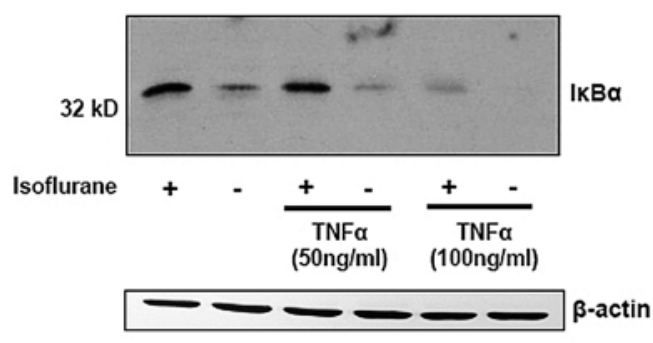

B

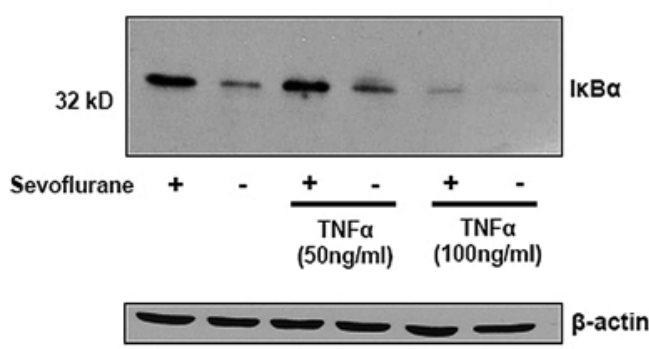

Figure 3. (A and B) Degradation of $\mathrm{I} \kappa \mathrm{B} \alpha$ in THP-1 cells 15 min after stimulation with $\mathrm{TNF}-\alpha$ as determined by Western blot analysis. Equal amounts of $50 \mu \mathrm{g}$ of protein were immunoblotted onto nitrocellulose membranes. Data shown are representative of three independent experiments.

activation and immigration of inflammatory cells during ischemic and inflammatory conditions $(1,2)$ as well as the release of proinflammatory cytokines $(15,16)$. The underlying molecular mechanisms are still not fully understood and are under intensive investigation.

The results of the present study suggest that exposure to volatile anesthetics sevoflurane and isoflurane attenuates release of IL-8 and expression of HO-1 in THP-1 cells through stabilization of $\mathrm{I} \kappa \mathrm{B} \alpha$ followed by a reduced translocation of $\mathrm{NF}-\kappa \mathrm{B}$ to the nucleus. Interestingly, this stabilization of $\mathrm{NF}-\kappa \mathrm{B}$ seems to be dependent on stabilization and, in part, upregulation of the intracellular IкB $\alpha$ content as observed under unstimulated conditions. However, this effect was only observed in the present study during exposure of the cells to sevoflurane with a peak at $8 \mathrm{~h}$, whereas isoflurane also stabilized I $\kappa \mathrm{B} \alpha$ but without increasing the intracellular content (data not shown).

We suggest that this is a specific pharmacological effect of sevoflurane due to the fact that this was not noted when the cells were exposed to isoflurane and that it occurred in a time-dependent manner. This might be related to the different chemical ultrastructure of the molecule compared to isoflurane. Focusing on the fact that the molecular pharmacology of volatile anesthetics is still not well-defined and the current theories imply that these drugs act in part through interfering with hydrophobic cavities of cellular proteins (21), it could be speculated that sevoflurane, with its different stereotactic structure as compared to isoflurane, changes the intrinsic activity of the protein $\mathrm{I} \kappa \mathrm{B} \alpha$ and acts with a more sustained and prolonged effect on the IкB $\alpha$ molecule.

The above mentioned observations in the present study reveal the importance of the $\mathrm{NF}-\kappa \mathrm{B}$ pathway in the initial phase of inflammatory responses. Previous findings suggest that reduced IкB $\alpha$ degradation is responsible for the antiinflammatory effect of volatile anesthetics under ischemic conditions $(22,23)$. Our present study demonstrated that, also during inflammatory situations, exposure to both volatile anesthetics stabilized $\mathrm{I}_{\kappa} \mathrm{B} \alpha$ in the cells and particularly sevoflurane additionally led to an upregulation in intracellular I $\mathrm{B} \alpha$ content.

\section{A}

\section{B}
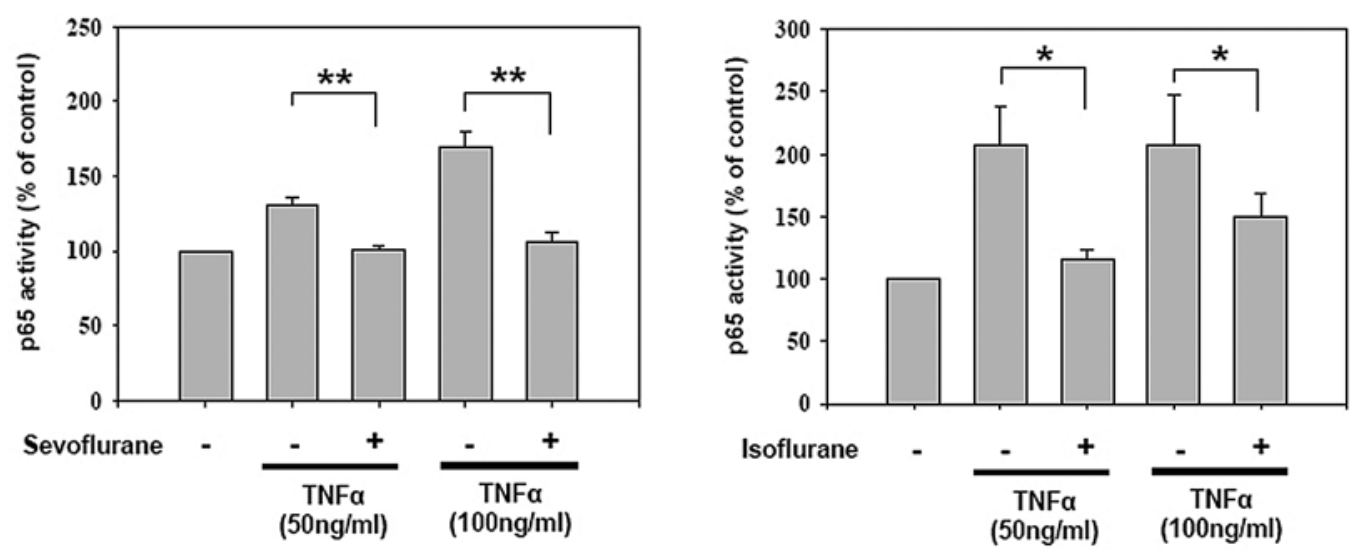

Figure 4. (A and B) Analysis of translocated, intranuclear activity of p65 subunit in THP-1 cells. For measurement, the ELISA-based Trans-AM NF- $\mathrm{B}$ kit was used. RNA was isolated from whole cell lysates, and total RNAs of $8 \mu \mathrm{g}$ were used for analysis according to the manufacturer's instructions. ${ }^{*} \mathrm{p}<0.05$, ${ }^{* *} \mathrm{p}<0.01, \mathrm{n}=3$. 
A

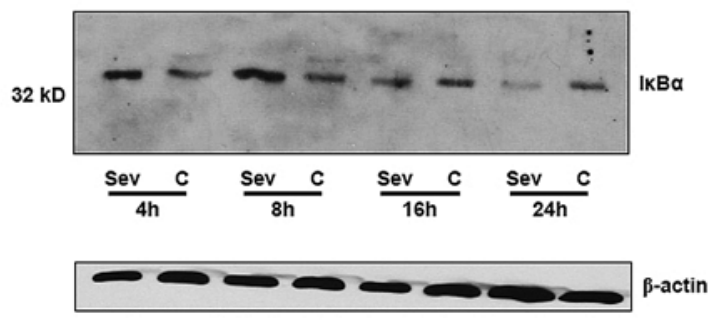

B

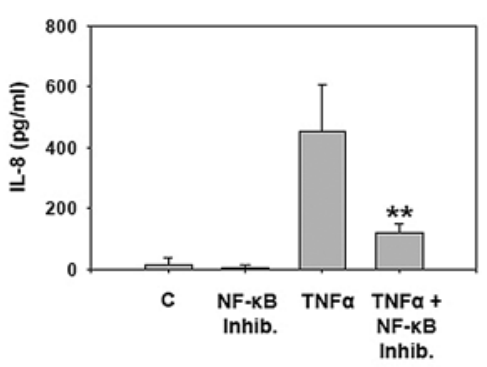

Figure 5. (A) Analysis of the amount of intracellular IкB $\alpha$ in THP-1 cells under unstimulated conditions exposed to volatile anesthetic sevoflurane (sev) as determined by Western blot analysis. Equal amounts of $50 \mu \mathrm{g}$ of protein were immunoblotted onto nitrocellulose membranes. Data shown are representative of three independent experiments. (B) Analysis of cytokine levels of IL-8 in cell-free culture supernatants determined by ELISA. Cells were incubated with either TNF- $\alpha(50 \mathrm{ng} / \mathrm{ml})$ alone or in combination with a specific inhibitor of NF-кB (BAY11-7085) for $16 \mathrm{~h}$. Controls were incubated with or without the inhibitor alone. Data are expressed as mean cytokine concentrations $\pm \mathrm{SD} ;{ }^{*} \mathrm{p}<0.05,{ }^{* *} \mathrm{p}<0.01, \mathrm{n}=4$.

In this context, it was also demonstrated that the mechanism of anti-inflammatory action of substances (e.g. dexamethasone) additionally depend on the upregulation of $\mathrm{I} \kappa \mathrm{B} \alpha$ content in treated cells, which then stabilizes NF-кB translocation to the nucleus (24).

To the best of our knowledge, this is the first study demonstrating the effects of volatile anesthetics on intracellular IкB $\alpha$ regulation in THP-1 cells under unstimulated conditions.

The present study also demonstrated that the intracellular expression of HO-1 was attenuated during exposure to both volatile anesthetics. HO-1 is regarded as a regulatory protein during inflammatory situations $(25,26)$. Therefore, the initial induction of HO-1 after TNF- $\alpha$ stimulation demonstrated in the present study is suggested to be a counter-regulation to avoid overstimulation of the proinflammatoric state of the cells. Most data favor an anti-inflammatory effect of HO-1 and its importance for the regulation of the inflammatory response (27) to prevent overwhelming inflammatory situations. We could not ascertain whether the downregulating effects of the volatile anesthetics on the HO-1 release would have deleterious effects in inflammatory situations in vivo, regarding its regulatory potential, and this issue requires further investigation.

Furthermore, studies suggest that exposure to volatile anesthetics, concurrently with their anti-inflammatory effects, also might impair the immune defense mechanisms during the perioperative period with a possible negative outcome for critical care patients (28). Several studies demonstrated that exposure to anesthetics contributed to postoperative immunosuppression, especially when administered in higher concentrations or for a longer period of time $(28,29)$. In particular, the modulation of lymphocyte function and induction of apoptosis in those cells seem to play a crucial role in immunosuppression $(28,30)$. Contradictory results also suggest a different role, as demonstrated in the present study, for sevoflurane and support a more anti-inflammatory pronounced impact of this substance. Whereas inhalational anesthetics such as halothane and nitrous oxide induced peripheral lymphocytopenia in patients undergoing elective hysterectomy, sevoflurane exposure had the opposite effect $(31,32)$ or did not influence lymphocyte apoptosis (33). If this is so, then the clinical impact is of interest and should be investigated in further clinical studies.

In conclusion, the present study demonstrated that exposure to the volatile anesthetics sevoflurane and isoflurane strongly attenuated IL-8-release and HO-1 expression in THP-1 cells. This was induced by a stabilization of intracellular IкB $\alpha$ and reduced NF-кB translocation. Regarding sevoflurane, the IкB $\alpha$ stabilization was suggested to be caused by an upregulation of intracellular I $\mathrm{K} \alpha \alpha$ protein. That this effect has clinical relevance is suggested by the following lines of evidence. First, this anti-inflammatory effect of the volatile anesthetics sevoflurane, isoflurane and desflurane was also demonstrated in animal models of inflammation $(6,18,34)$ and with human cells from healthy donors (35). Second, the inhibitory properties on the IкB $\alpha$ degradation and inducing properties on I $\mathrm{B} \alpha$ protein content occurred at concentrations comparable to those used during sevoflurane or isoflurane inhalation in clinical practice (36). Whether other volatile anesthetics (e.g. halothane, desflurane) have similar effects on intracellular $\mathrm{I} \kappa \mathrm{B} \alpha / \mathrm{NF}-\kappa \mathrm{B}$ regulation requires further investigation.

\section{Acknowledgements}

The study was supported by a Grant of the Else-KrönerFresenius-Stiftung to K.A.B.

\section{References}

1. Zaugg M, Lucchinetti E, Garcia C, Pasch T, Spahn DR and Schaub MC: Anesthetics and cardiac preconditioning. Part II Clinical implications. Br J Anaesth 91: 566-576, 2003.

2. De Hert SG: The concept of anaesthetic-induced cardioprotection: clinical relevance. Best Pract Res Clin Anaesthesiol 19: 445-459, 2005

3. Zaugg M, Lucchinetti E, Uecker M, Pasch T and Schaub MC: Anaesthetics and cardiac preconditioning. Part I. Signalling and cytoprotective mechanisms. Br J Anaesth 91: 551-565, 2003.

4. Tanaka T, Ludwig LM, Kersten JR, Pagel PS and Warltier DC: Mechanisms of cardioprotection by volatile anesthetics. Anesthesiology 100: 707-721, 2004.

5. Hofstetter C, Flondor M, Boost KA, Koehler P, Pfeilschifter J, Zwissler B and Muehl H: A brief exposure to isoflurane (50 seconds) markedly impacts on plasma cytokine levels in endotoxemic rats. Int Immunopharmacol 5: 1519-1522, 2005. 
6. Plachinta RV, Hayes JK, Cerilli LA and Rich GF: Isoflurane pretreatment inhibits lipopolysaccharide-induced inflammation in rats. Anesthesiology 98: 89-95, 2003.

7. Ghosh S, May MJ and Kopp EB: NF-кB and Rel proteins: Evolutionary conserved mediators of immune responses. Annu Rev Immunol 16: 225-260, 1998.

8. Barnes PJ and Karin M: Nuclear factor-кB: A pivotal transcription factor in chronic inflammatory diseases. N Eng J Med 336: 1066-1071, 1997.

9. Karin M: How NF-кB is activated: The role of the IкB kinase (IKK) complex. Oncogene 18: 6867-6874, 1999.

10. Ea CK, Deng L, Xia ZP, Pineda G and Chen ZJ: Activation of IKK by TNFalpha requires site-specific ubiquitination of RIP1 and polyubiquitin binding by NEMO. Mol Cell 22: 245-257, 2006.

11. Chen G and Goeddel DV: TNF-R1 signalling: a beautiful pathway. Science 296: 1634-1635, 2002.

12. Ware LB and Matthay MA: The acute respiratory distress syndrome. N Engl J Med 342: 1334-1349, 2000.

13. Mukaida N, Matsumoto T, Yokoi K, Harada A and Matsushima K: Inhibition of neutrophil-mediated acute inflammation injury by an antibody against interleukin-8 (IL-8). Inflamm Res 47 (Suppl 3): 151-157, 1998.

14. Boyle EM Jr, Kovacich JC, Hebert CA, Canty TG Jr, Chi E, Morgan EN, Pohlman TH and Verrier ED: Inhibition of interleukin-8 blocks myocardial ischemia-reperfusion injury. $\mathbf{J}$ Thorac Cardiovasc Surg 116: 114-121, 1998.

15. Giraud O, Seince PF, Rolland C, Lecon-Malas V, Desmonts JM, et al: Halothane reduces the early lipopolysaccharide-induced lung inflammation in mechanically ventilated rats. Am J Respir Crit Care Med 162: 2278-2286, 2000.

16. Helmy SA and Al-Attiyah RJ: The effect of halothane and isoflurane on plasma cytokine levels. Anaesthesia 55: 904-910, 2000.

17. De Rossi LW, Brueckmann M, Rex S, Barderschneider M, Buhre W, et al: Xenon and isoflurane differentially modulate lipopolysaccharide-induced activation of the nuclear transcription factor $\mathrm{\kappa B}$ and production of tumor necrosis factor-alpha and interleukin-6 in monocytes. Anesth Analg 98: 1007-1012, 2004

18. Boost KA, Hofstetter C, Flondor M, Betz C, Homann M, Pfeilschifter J, Muehl $\mathrm{H}$ and Zwissler B: Desflurane differentially affects the release of proinflammatory cytokines in plasma and bronchoalveolar fluid of endotoxemic rats. Int J Mol Med 17: 1139-1144, 2006.

19. Moudgil GC, Allan RB, Russell RJ and Wilkinson PC: Inhibition, by anaesthetic agents, of human leucocyte locomotion towards chemical attractants. Br J Anaesth 49: 97-105, 1977.

20. Giraud O, Molliex S, Rolland C, Lecon-Malas V, Desmonts JM, et al: Halogenated anesthetics reduce interleukin-1beta-induced cytokine secretion by rat alveolar type II cells in primary culture. Anesthesiology 98: 74-81, 2003.

21. Eckenhoff RG: Promiscuous ligands and attractive cavities: how do the inhaled anesthetics work? Mol Interv 1: 258-268, 2001.
22. Zhong $\mathrm{C}$, Zhou $\mathrm{Y}$ and Liu H: Nuclear factor kappaB and anesthetic preconditioning during myocardial ischemiareperfusion. Anesthesiology 100: 540-546, 2004.

23. Li Y, Zhang X, Zhu B and Xue Z: Desflurane preconditioning inhibits endothelial nuclear factor-kappa-B activation by targeting the proximal end of tumor necrosis factor-alpha signaling. Anesth Analg 106: 1473-1479, 2008.

24. Castro-Caldas M, Mendes AF, Carvalho AP, Duarte CB and Lopes MC: Dexamethasone prevents interleukin-1beta-induced nuclear factor-kappaB activation by upregulating IkappaB-alpha synthesis, in lymphoblastic cells. Mediators Inflamm 12: 37-46, 2003.

25. Bauer M, Huse K, Settmacher U and Claus RA: The heme oxygenase-carbon monoxide system: regulation and role in stress response and organ failure. Intensive Care Med 34: 640-648, 2008.

26. Takahashi T, Morita K, Akagi R and Sassa S: Heme oxygenase1: a novel therapeutic target in oxidative tissue injuries. Curr Med Chem 11: 1545-1561, 2004.

27. Jin Y and Choi AM: Cytoprotection of heme oxygenase-1/ carbon monoxide in lung injury. Proc Am Thorac Soc 2: 232-235, 2005.

28. Salo M: Effects of anaesthesia and surgery on the immune response. Acta Anaesthesiol Scand 36: 201-220, 1992.

29. Peric M, Vranes Z and Marusic M: Immunological disturbances in anaesthetic personnel chronically exposed to high occupational concentrations of nitrous oxide and halothane. Anesthesia 46: 531-537, 1991 .

30. Loop T, Dovi-Akue D, Frick M, Roesslein M, Egger L, Humar M, Hoetzel A, Schmidt R, Borner C, Pahl HL, Geiger KK and Pannen BH: Volatile anesthetics induce caspase-dependent, mitochondria-mediated apoptosis in human T lymphocytes in vitro. Anesthesiology 102: 1147-1157, 2005.

31. Rem J, Brandt MR and Kehlet H: Prevention of postoperative lymphopenia and granulocytosis by epidural analgesia. Lancet 1: 283-284, 1980.

32. Morisaki H, Aoyama Y, Shimada M, Ochiai R and Takeda J: Leucocyte distribution during sevoflurane anaesthesia. Br J Anaesth 80: 502-503, 1998

33. Goto Y, Ho SL, McAdoo J, Fanning NF, Wang J, Redmond HP and Shorten GD: General versus regional anaesthesia for cataract surgery: Effects on neutrophil apoptosis and the postoperative pro-inflammatory state. Eur J Anaesthesiol 17: 474-480, 2000.

34. Hofstetter C, Boost KA, Flondor M, Basagan-Mogol E, Betz C, Homann M, Muhl H, Pfeilschifter J and Zwissler B: Antiinflammatory effects of sevoflurane and mild hypothermia in endotoxemic rats. Acta Anaesthesiol Scand 51: 893-899, 2007.

35. Mitsuhata H, Shimizu R and Yokoyama MM: Suppressive effects of volatile anesthetics on cytokine release in human peripheral blood mononuclear cells. Int Immunopharmacol 17: 529-534, 1995.

36. Eckenhoff RG and Johansson JS: What are 'relevant' concentrations? Anesthesiology 95: 1537-1539, 2001. 